\title{
Aquém, em e além do conceito: comunicação, epistemologia e compreensão*
}

\begin{abstract}
RESUMO
O texto propõe uma aproximação de tipo compreensivo ao campo da comunicação, a seu objeto e a suas teorias. Não abdica da razão e da ciência, mas se indispõe contra a soberania absoluta do signo da explicação em discursos que a partir delas se produzem e reproduzem. É contra a transformação do conceito em camisa-de-força a negar o direito à intuição criadora; o direito à formulação de noções, símbolos e imagens com densidade interpretativa; à dialogia entre saberes; às incursões por territórios trans- e não-disciplinares. Interroga criticamente o modelo dominante de pensamento que pensa pensar a comunicação e que é herdeiro, em não pequena medida, de uma visão racionalizadora dos acontecimentos, do real, da vida.
\end{abstract}

\section{PALAVRAS-CHAVE}

comunicação

epistemologia

compreensão

\section{ABSTRACT}

The text claims for an understanding approach to Comunication Studies, its object and theories. Although this approach does not give up reason and science, it goes against the dominion of its explanation as a rule in discourses. This text also makes the point against the use of concepts as a one-size-fitsall solution which denies the right to creative intuition, to create interpretative notions, symbols and images; to the right to go through interdisciplinary and also transdisciplinary territories. The article also criticizes the current mainstream ideas about communication, since it is the heir of a rational view of the real world, of events and life.

\section{KEY WORDS}

communication

epistemology

compreehension
Que tipo, modelo ou forma de pensamento pensa a comunicação, seu campo de estudo, suas teorias e práticas? A pergunta é pertinente, tanto mais porque quando, por exemplo, a conversa tem como tema as teorias da comunicação, é possível considerar, com Berger, em artigo escrito em 1991, que o problema é que elas são poucas. Ou que são muitas, como rebate Craig, dois anos depois, ambos traduzidos e publicados no Brasil por Martino (2007), num livro cujo título levanta justamente a pergunta se são muitas ou poucas essas teorias. $\mathrm{O}$ organizador da obra brinca na construção do título do texto que antecede as reflexões dos dois teóricos estrangeiros: "Uma questão prévia”, propõe: "Existem teorias da comunicação?"

\section{Comunicação, ciência e rigor}

Pergunta nada discreta. O brasileiro examina o problema de perto, em autores reconhecidos e suas obras. Faz as contas do significado numérico da brincadeira. Há a crença, afirma ele, por trás da idéia da existência de não se sabe quantas teorias da comunicação, de que elas "existem a despeito de todo e qualquer obstáculo colocado à sua definição. Cremos em sua existência, e isso parece nos bastar" (Martino, 2007, p. 14). Ora, uma crença, como ensina a velha e prestigiada tradição disciplinar, pode representar muita coisa, menos um alicerce sólido para a construção de um pensamento rigoroso, científico.

Os números, em se mantendo o observador nessa ótica, são reveladores. Consultados os livros de teorias da comunicação em língua espanhola, Martino observa que "nenhuma teoria é comum a todas as obras" e que "quase 2/3 das teorias apresentadas não têm correspondência entre os pares (aparecem apenas em uma obra)" (Martino, 2007, p. 21) $)^{1}$. O estudioso chama a atenção para a imensidão do buraco:

Em geral, não é apresentada nenhuma definição de "teoria". Há pouco cuidado ou ausência de definição do conceito de "comunicação". Nenhum livro analisado apresentou sequer um critério explícito para justificar a seleção das teorias apresentadas (o que demonstra de forma inequívoca a pouca exigência em matéria de critérios de pertinência das teorias em relação à área de comunicação). Em última instância, o que estes dados nos mostram é que não temos uma idéia muito precisa do que é teoria da comunicação (Martino, 2007, pp. 21-22).

Operando no ambiente intelectual dos conceitos, critérios e definições, da exigência de clareza e de rigor, e

\author{
Dimas A. Künsch \\ Coordenador do Programa de Pós-Graduação da Faculdade Cásper \\ Líbero/SP/BR \\ dimaskunsch@facasper.com.br
}


tendo em mãos esse conjunto de dados e de descobertas, imaginar que "não temos uma idéia muito precisa do que é teoria da comunicação" não passa de uma atitude de generosidade ímpar.

Martino deixa-se conduzir, com plena consciência, por essa exigência de rigor científico. Revolta-se contra certos discursos e propostas interdisciplinares que the parecem, digamos, de caráter indolente, incapazes de agarrar o desafio de, na comunicação, "dar as razões de nossa esperança", como expressa uma frase bíblica (1 ${ }^{\mathrm{a}}$ Carta de Pedro 3,15). As partes do texto citado mostram que Matino cobra critérios, definições, conceitos. Reivindica clareza. Pensa seriamente no campo da comunicação, em seu objeto e nas teorias que com esse objeto se entretêm. E possui, como robusto background, uma longa e bem sedimentada herança acadêmica, quando se leva em conta a mais nobre, prestigiosa - e dominante vertente do conhecimento, que traz a assinatura do pensamento científico moderno.

Inclusive, os produtos contemporaneamente mais recentes resultantes dessa herança, na área em tresloucado movimento da informação e da comunicação, acalentam os sonhos dos mais otimistas, enquanto, simultaneamente, deixam às vezes de péssimo humor o alto comando do ministério da saudade e neoluditas de índole diversa. Como sublinha Martino em outra obra, é por certo viável pensar a comunicação sob os mais diferentes pontos de vista ou formas de conhecimento. Mas "seria possível fazer teoria da comunicação sem situá-la no plano da ciência?", ele pergunta. "Não, não seria", responde. "O termo teoria só se aplica à ciência. Ou, dito de outra maneira: apenas na ciência o termo teoria encontra seu sentido específico, e não um sentido genérico" $(2008$, p. 15).

\section{Contra a hegemonia do signo da explicação}

A longa e caudalosa tradição científica referida estende formalmente suas raízes lá para trás no tempo, até a Grécia Antiga, embora assuma seu evidente rigor, vigor, e às vezes rancor a partir do início da modernidade, com nomes como Bacon, Galileu e outros, conhecidos e reconhecidos na gramática que estabelece regras para o exercício metodicamente responsável da razão positiva. Atinge um momento de olimpiana desenvoltura em um René Descartes à procura, sofrida - para não se separar jamais razão e paixão, no sentido de passio -, de idéias claras e distintas, de evidência e certeza, convencendose, ao final, de que "as coisas que concebemos mui clara e distintamente são todas verdadeiras", ainda que não se consiga "distinguir bem quais são as que concebemos distintamente" (Descartes, 1996, p. 38).

Não é o caso de se empenhar para traçar um roteiro possível do percurso que vai das origens modernas dessa tradição empírico-racional aos dias de hoje, passando por Isaac Newton, pelo pensamento autoconscientemente iluminado do Iluminismo, o positivismo comtiano e o historicismo do senhor Hegel, entre outros nomes e temas. De fato, esse não é o objetivo do texto que aqui se apresenta. Porém, desde já, numa ligeira abertura ao pensamento compreensivo, convém anotar que o senhor Renatus Cartesius - para além da observação, nada curiosa, de que não é fácil como às vezes se pensa saber quais as coisas que "concebemos distintamente" - aplica um colorido especial ao edifício sólido que sonha construir sobre o cemitério da Escolástica, quando, no Discurso do Método, abandona por mais de uma vez a linguagem dissertativa para, tão encantado quanto, apropriar-se do discurso narrativo. Conta a sua história, diz, sem pretender "ensinar [...] o método que cada um deve seguir para bem conduzir sua razão". Seu tão celebrado discurso não passa, em suas próprias palavras, de "uma história", ou, mais, de "uma fábula" (1996, p. 7) - e a essas tintas em nada invisíveis de liberdade discursiva, quase de poesia, dou o nome, em outro texto, de "o cogito compreensivo cartesiano" (Künsch, 2008, pp. 178-179).

Ainda, nesse mesmo contexto, não é igualmente de se desconsiderar o fato de que a crítica aqui proposta ao modelo de pensamento empírico-racionalista não dura muito tempo para ser desclassificada, às vezes com violência, como se fosse uma postura retrógrada de descrédito na ciência, quando não de apologia ignorante do obscurantismo. Não convém se assustar com certo tipo de reação, não exatamente racional nem tampouco científica, de um pensamento aqui e acolá arredio à crítica, por ter se habituado a pôr pontos finais lá onde interrogações, vírgulas, ponto-e-vírgulas e reticências ofereceriam maior garantia na difícil arte de exorcizar o dogmatismo e abrir o terreno à compreensão. Aos herdeiros obstinados do signo das explicações finais vale o recado, irado, contra "a paranóia habitual com que convivem todos os que se pretendem detentores de um saber absoluto". "Vamos deixá-los para lá, entregues à sua crença nos poderes da ciência e às voltas com os diversos dialetos nos quais ela costuma exprimir-se. Tal arrogância não mais se recomenda" (Maffesoli, 2007, p. 16).

Esse autor considera que, "bem além do conceito fechado, totalitário, irrefreável", podem refulgir, no discurso, "a noção, a metáfora, a analogia e a correspondência, sempre aptas a captar todos os matizes de uma realidade complexa". Repudia a "brutalidade" no tratamento das questões sociais, para propor que "mais vale saber desembaraçar, com paciência, seus múltiplos fios entrelaçados". Aponta o dedo tanto contra a preguiça intelectual quanto contra o dogmatismo, exercitando-se no discurso em defesa de uma "visada compreensiva", na sociologia como nas demais áreas do saber científico e de outros saberes (Maffesoli, 2007, p. 17). Provoca:

Talvez não seja inútil fazer referência a uma situação paroxísmica, perfeitamente patológica no caso em pauta, para fazer sobressair bem o perigo de uma atitude de espírito que "corta", separa, funcio- 
na a esmo, sem referência ao real naquilo que este tem de tangível, de palpável, de inteiro. A "esquize" do racionalismo não fornece senão uma épura do homem e do mundo. Produz um esquema que apresenta características importantes, mas ao qual falta o essencial: a vida (Maffesoli, 1998, p. 31).

Sempre com muito estilo e um discurso bem torneado, Maffesoli perde de vez o estilo quando empunha as armas de um pensamento que se advoga compreensivo para denunciar, com a força que julga advir da sábia "douta ignorância", o que chama de "terrorismo do conceito". Pode não ser conveniente pensar assim. Até porque a força e a contínua ameaça da "lógica arrasadora da guerra", que, na acepção de Restrepo, impregna o modelo de pensamento científico moderno (1998, p. 13), não fornecem salvo-conduto a ninguém no pantanoso terreiro da arrogância. Melhor acalentar a idéia de que um ponto de vista compreensivo possa e deva se fazer e refazer no diálogo com o diferente e, inclusive, na disposição a se compreender a própria incompreensão, como sugere Morin. "A ética da compreensão", afirma, "é a arte de viver que nos demanda, em primeiro lugar, compreender de modo desinteressado. Demanda grande esforço, pois não pode esperar nenhuma reciprocidade". Vai mais fundo nessa exigência: "A ética da compreensão pede que se compreenda a incompreensão" (2000, p. 99). Sem garantia de sucesso, convém reforçar.

\section{Comunicação e compreensão}

A compreensão, porém, tanto em seu significado cognitivo original de cumprehendere (juntar, abraçar, integrar), quanto em seus conteúdos intersubjetivos - com os laços complexos que unem um e outro significado -, está longe de estipular a renúncia a uma tomada de posição, nem, muito menos, a capitulação ingênua a um relativismo tout court. A compreensão prefere a noção ao conceito - sem negar o conceito em sua real fertilidade teóricoexplicativa. Opta por uma razão aberta e fértil que vai de encontro ao racionalismo. Elege a multiperspectividade ou multiangulação no tratamento das questões. Em propondo tudo isso, a "visada compreensiva" identifica, sim, no modelo duro do pensamento científico moderno uma força e um esplendor talvez apenas comparáveis à força e à insensatez com que esse vitorioso modelo é capaz de menosprezar, ignorar ou simplesmente negar tudo quanto ele mesmo é incapaz de submeter ao império do método-metro, da régua e do esquadro.

No mais, a crítica à saturação do conceito deixou hoje de representar uma novidade, sendo capaz de apresentar facilmente seus comprovantes de residência e uma mais ou menos extensa lista de assinaturas. Nos trilhos crescentemente movimentados do sensível e do afeto, Sodré, por exemplo, adverte para a "urgência de outra posição interpretativa para o campo da comunicação, capaz de liberar o agir comunicacional das concepções que o limitam ao nível de interação entre forças puramente mecânicas e de abarcar a diversidade da natureza das trocas, em que se fazem presentes os signos representativos ou intelectuais, mas principalmente os poderosos dispositivos do afeto". Está preocupado com o "que está aquém ou além do conceito" (2006, pp. 12-13). Condena a "ditadura lógica da razão enquanto domínio universal" (Sodré, 2006, p. 27). Vê, no "surgimento de "outra cultura", vertebrada pelas tecnologias da informação", a exigência "de outra atitude epistemológica ou interpretativa - mais compreensiva, menos intelectualracionalista, capaz de apreender os fenômenos fora da medida universal - para a análise que se pretende chamar de 'comunicacional'" (Sodré, 2006, p. 14). Insiste no "conhecimento compreensivo":

Na base de uma experiência ontológica da comunicação (em termos de ciência, política e vivência), encontra-se o problema da compreensão, suscitado pela vinculação inerente ao comum. O entendimento e a explicação se obtêm por meio das interpretações que fazemos do mundo a partir de nossos habituais quadros conceituais. A compreensão, porém, fica além desses circuitos autolegitimativos, fora dos puros atos de linguagem" (Sodré, 2006, p. 67).

Sodré, no trecho citado, parece não atentar para o dado de que os "circuitos autolegitimativos" do entendimento e da explicação, tanto quanto o terreno delimitado pelas experiências situadas "fora dos puros atos de linguagem", podem igualmente-e, imagino que devam, com ganhos para o conhecimento - ser abarcados pelas luzes da compreensão, em processos que reconheçam na atitude compreensiva, tanto no nível da objetividade quanto da intersubjetividade, um verdadeiro estatuto cognitivo. Essa percepção se faz tanto mais necessária, nesse contexto, quanto mais se levar a sério a crítica do próprio autor à "ditadura lógica da razão enquanto domínio universal", de que se falou antes. Com efeito, ditadura não rima com compreensão, em nível algum.

Por outro lado, o acento que o autor coloca nos atos vinculatórios, na associação entre as noções de comunicação e de compreensão, ajuda a ressaltar certo malestar gerado por delimitações que se podem chamar de não compreensivas do campo da comunicação. Como, por exemplo, quando Venício A. de Lima, no que ele denomina primeira "qualificação", estabelece:

A comunicação cujo campo de estudos nos interessa é aquela que aparece tardiamente na história da humanidade e se constitui numa das importantes características da modernidade. Vale dizer, a comunicação que se distingue da comunicação humana stricto sensu pelo uso de tecnologias específicas e pelo surgimento de instituições. Contemporaneamente é 
aquela a que se convencionou chamar meios de comunicação de massa (mass media) ou mídia (2004, p. 23).

À parte o desconfortável acúmulo de interrogações acerca de conceitos como os de "meios de comunicação" e de "comunicação de massa", e sem levar muito em conta, também, as dificuldades de se chegar a qualquer tipo de acordo sobre os significados técnicos, culturais e sociais do "uso de tecnologias específicas", em tempos de novas e sempre mais novas tecnologias de informação e de comunicação - ainda que se possa reconhecer como possível e teoricamente legítimo o recorte feito pelo autor -, soa estranha a idéia de que esse mesmo autor, "primariamente", não esteja interessado "na comunicação entendida como processo social básico e elemento constitutivo da própria natureza humana" (Lima, 2004, p. 23). Trata-se, com efeito, de um preço alto demais a ser pago pela liberdade de se eleger tecnologias frente àquilo, e tudo aquilo, que Lima chama de "comunicação humana stricto sensu".

O mesmo mal-estar perpassa as preocupações de Martino quando ele, ao inventar de definir "o que é comunicação", constata que essa é "uma pergunta embaraçosa". As razões são muitas, ele esclarece, e uma das primeiras advém do fato de que "não se pode ignorar ou reivindicar o desconhecimento do que vem a ser a comunicação sem deixar de comprometer a coerência de nossa inserção como profissionais ou pesquisadores do campo da comunicação" (2001, p. 11). A observação é plena de conteúdo simbólico. Mas, ainda que movido pela consciência de que "não se trata de achar a verdade ou eleger um único sentido em detrimento dos vários usos do termo" comunicação, a própria interrogação que serve de título ao capítulo - "De qual comunicação estamos falando?" -, qualquer que seja a escolha, deixa transparecer uma estreita aproximação entre esta e a atitude ou abordagem anterior, de Lima. Além disso, retomando o sentido de comunicação-vinculação trazido à discussão por Sodré, poder-se-ia acrescentar, ao tema levantado por Martino, do embaraço por não se saber direito o que é aquilo de que se está falando e com o que se trabalha, a idéia, não menos relevante, de que pessoas se comunicam ou não se comunicam - inclusive lá onde às vezes sofrem, outras vezes se alegram, em geral nutrem a esperança de dizer com menos impropriedade possível o que é comunicação.

Em suma, na prática, stricto e lato sensu são dimensões inseparáveis na comunicação, como deveriam sê-lo, também, nos estudos dos fenômenos comunicacionais, sem com isso negar a ninguém o direito de fazer os recortes que julgar convenientes, nos caminhos dessa busca coletiva de compreensão. Nunca é demais, no entanto, recordar, situando-nos agora no quadro da comunicação stricto sensu, a lamentável constatação de Morin, ao discorrer sobre a compreensão, de que "o mundo dos intelectuais, escritores ou universitários, que deveria ser mais compreensivo, é o mais gangrenado sob o efeito da hipertrofia do ego, nutrido pela necessidade de consagração e de glória" (2000, p. 97).

O debate sobre a existência, a força e as mutilações culturais, humanas e sociais provocadas pela incomunicação, se não desqualifica - compreensivamente falando - uma abordagem com acento ou recorte em tecnologias antigas ou novas, traz para o centro das atenções quanto afirmado por Maffesoli, em texto já citado, sobre o que ele considera a "falta essencial" do modelo do racionalismo moderno: "a vida". Em outro texto, dedico umas tantas linhas à ética epicurista, do prazer advindo do uso inteligente da razão vinculada à idéia de philia, amizade. A comunicação entre os pares pode-se compreender isso hoje assim, contribui para a saúde do corpo e do espírito, a vitória sobre o medo, a dor e a própria morte, ensinava Epicuro, por volta do ano 300 antes de Cristo (Künsch, 2008, pp. 184-185).

\section{Ecos na Compós, ano 2007}

Um dos textos selecionados pelo Grupo de Trabalho (GT) "Epistemologia da Comunicação" para o XVII Encontro da Compós - a Associação Nacional dos Programas de Pós-Graduação em Comunicação -, realizado em São Paulo, SP, em junho de 2008, assinado por Francisco José Paoliello Pimenta, é particularmente interessante de ser lembrado, em suas múltiplas relações com os conteúdos aqui discutidos: "Indeterminação; o 'admirável'; a crescente comunicabilidade". Nele, Pimenta retoma nove dos dez trabalhos selecionados para a Compós do ano anterior, em Curitiba, PR, e argumenta que, "embora sustentados em vertentes de análise bastante diferentes", esses trabalhos "têm, curiosamente, em comum suas ênfases relacionadas a fenômenos caracterizados como "incertos", da esfera do "sensível", "intuitivos", "subjetivos", marcados pela "diversidade", "despercebidos" e "instáveis"” (2008, p. 1). Haveria, portanto, uma "convergência de posturas epistemológicas", afirma Pimenta, "frente ao problema da configuração do campo da Comunicação no País".

Não irei aprofundar a idéia, defendida pelo autor, de que "a categoria semiótica da Primeiridade e o conceito a ela associado de "esteticamente admirável", de Charles S. Peirce, podem ser úteis para entendermos esta convergência de posturas epistemológicas" (Pimenta, 2008 , p. 1). Chama a atenção, no entanto, a hipótese de que essas ênfases todas, diversas, mas convergentes, como entende o autor, " poderiam estar associadas a um mero sentimento de crescente compartilhamento comunicacional, permitido pela atual rede mundial de computadores e sua tecnologia digital":

[...] a comunicação imediata, planetária, ubíqua, portátil e em rede poderia estar conduzindo a um sentimento coletivo admirável, que, no limite, conduziria ao Summum Bonum, do qual os autores citados não só participam como começam a gerar uma au- 
toconsciência dele e a tentar explicitá-lo (Pimenta, 2008$, p. 11$)^{2}$.

Não é preciso subestimar a importância, os desafios teóricos e práticos que levantam e as mudanças culturais que provocam a rede mundial de computadores e as tecnologias digitais. Todavia, parece forçada a idéia de se associar tão fortemente aquilo que Pimenta chama de "convergência de posturas epistemológicas", a partir da leitura que faz dos textos desses autores, aos novos fenômenos do universo da informação e da comunicação. Três exemplos, retirados com certa liberdade metodológica dentre os nove que ele cita, ajudam a identificar, nos autores em questão, a presença, às vezes incômoda para o establishment científico, de conteúdos e percepções mais facilmente associáveis àquilo que estou entendendo como crise do conceito e do signo da explicação.

É o caso de Malena Contrera, em seu texto "Em meio ao desencanto: a comunicação fundada no pensamento mecânico-funcional". Ela critica enfaticamente o cartesianismo, o mecanicismo e o funcionalismo que teriam impregnado, entre outros, o universo em desencanto dos estudos comunicacionais. Convida a uma revisitação do campo onde a vida tantas vezes contradiz e nega a lógica, ressalta a importância da consciência e da vinculação entre os sujeitos e imagina, assim, a possibilidade de "trazer vida a uma teoria da comunicação, aproximando-a (ainda que incomodamente) do terreno incerto e incontrolável da alma humana" (Contrera, 2007, p. 11).

Regina Rossetti, por sua vez, numa proximidade indiscutível com as proposições de Contrera, sublinha o valor da intuição no enfrentamento do tema da comunicação e recupera para o discurso a vitalidade da linguagem das imagens e metáforas. Considera fundamental "transcender conceitos rígidos", "libertar-se de conceitos pré-fabricados", para, como sugere Bergson, "criar "representações flexíveis, móveis, quase fluidas, sempre prontas a se moldarem sobre as formas da intuição"". Busca inspiração na arte, para afirmar, apoiando-se em Brincourt, "o sentido de uma linguagem capaz de sugerir o ser mais do que dizê-lo". Vê nisso, com Santaella, "um dos motivos da convergência entre comunicação e artes na cultura contemporânea como superação da tradicional fronteira entre ciência e arte" (Rossetti, 2007, p. 13).

O terceiro exemplo é o trabalho de Maria Immacolata Vassallo de Lopes, "Comunicação, disciplinaridade e pensamento complexo". Depois de traçar a rápida história da disciplinarização das ciências humanas e sociais, a autora remete ao diálogo com o pensamento da complexidade e junta argumentos em defesa da transdisciplinaridade. O paradigma da complexidade, no seguimento das idéias de Morin, como assume a autora, "incita a distinguir e fazer comunicar, em vez de isolar e de disjuntar" [...] e "a dar conta dos caracteres multidimensionais de toda a realidade" (Lopes, 2008, pp. 13-14).
Nessa mesma linha compreensiva de pensamento ("complexo-compreensiva", como tenho insistido em trabalhos anteriores, tanto para aproximar as duas noções no muito que têm em comum, como para distinguir aquilo que, na compreensão, vai além da idéia original de complexus - que é a de tecer e entretecer em conjunto -, para atingir o terreno de uma ética compreensiva), a autora, no percurso de sua argumentação, visita rapidamente a idéia de "fim das certezas" (Prigogine), para consolidar-se na crítica à disciplinarização nos domínios da ciência e na valente defesa da transdisciplinaridade (ou pós-disciplinaridade). "A transdisciplina", explicita a autora em primeiro lugar, "não busca manipular o que acontece no interior da disciplina, mas o que sucede quando ela se abre, ou melhor, se quebra. Trata-se, portanto, de uma ruptura de outro nível, aquele que transborda as disciplinas arrancando-as de si mesmas". Esse movimento de abertura e de transbordamento não possui caráter meramente tático, "mas implica uma perda da certeza quando uma disciplina começa a sentir que não é dona de seu objeto". A "quebra e abertura" das disciplinas, no sentido colocado, nos situa, a meu ver, e de maneira contundente, no quadro das possibilidades e virtualidades do pensamento compreensivo, se atribui às palavras da autora todo o mérito de que parecem investidas:

[...] a transdisciplina não somente quebra e abre as disciplinas, mas também as transborda pelo estabelecimento de relações cada vez mais densas não somente entre ciências humanas e sociais, mas das ciências com as artes, com a literatura, com a experiência comum, com a intuição, com a imaginação social. Pois não se trata somente de uma interação de discursos em termos de lógicas científicas, mas também da interação de discursos em termos de diversidades de linguagens e escrituras (Lopes, 2008, pp. 15-16).

Encontra-se aí, nas idéias de ruptura e de transbordamento, e, simultaneamente, na proposição de um adensamento das relações entre as ciências e outros saberes, um vigoroso estímulo ao direcionamento do olhar para o aquém e o além do conceito. Tanto mais porque, como adverte a autora, a história da constituição das várias disciplinas tem mostrado como o termo disciplina assume com frequiência a conotação de doutrina. O ponto de partida para a ação de quebra do rigor disciplinar pretende-se compreensivo: um ponto de vista que dialoga, junta, abraça, isto é, que não refuta, simplesmente, lançando na lata do lixo, o que não cabe nas praças renovadas das novas intuições teóricas. Inclui, nesse sentido e situa-se aí, também, o "em" do título deste artigo, ou "no" conceito - a percepção de que "a transdisciplinaridade não é o oposto das disciplinas, mas complementar a elas", diz Lopes, "pois que este novo rumo do conhecimento só tem sido possível com base em toda a riqueza 
de saberes produzida pelas distintas disciplinas, e é precisamente essa a base que tem permitido e exigido dar um salto à frente e passar para um pensamento transdisciplinar" (Lopes, 2008, p. 15).

\section{De novo a Compós, ano 2008}

Ecos do que Lopes chama de "novo rumo do conhecimento" são perceptíveis também em textos do Encontro da Compós em 2008. Melhor prova disso é o trabalho apresentado por Pimenta. Dois exemplos sirvam como ilustração: "Radical indeterminação: epistemologia e objeto científico da comunicação", assinado por Lucrécia D'Alessio Ferrara, e "Controvérsias sobre a cientificidade da linguagem", de Irene Machado.

Já o título do primeiro é sintomático - "Radical indeterminação" -, pois libera o sujeito do conhecimento da dureza do conceito e o projeta no caminho da busca, nesse território em geral sem muito apelo da epistemologia. Ferrara assinala que, como "meio interativo", a comunicação dispõe hoje de "sólidas promessas de outras e, talvez, novas propostas científicas". Essa "nova epistemologia", ou possibilidade de, se constitui na superação de "parâmetros tradicionais para considerar um objeto que, como potencialidade de base científica é, sobretudo, ambivalente: imprevisível, mas complexo; móvel, mas indeterminado; instigante, mas banal". A epistemologia da comunicação, com base nesse entendimento, necessita de "outros desenhos teóricos na revisão de suas bases tradicionais e outros recursos metodológicos na observação da realidade social e cultural" (Ferrara, 2008, p. 1). Tendo em mente a condição de complexidade do objeto da comunicação, volta-se, com Bourdieu, contra "certo dogmatismo que impede o exercício vital da ciência". Crê na possibilidade de se "pensar uma epistemologia fluida e em constante revisão do postulado de inteireza e totalidade que tem consagrado a ciência ocidental desde o século das Luzes" (Ferrara, 2008, p. 13). Esse "outro perfil científico" para a epistemologia da comunicação "seria tão paradoxal quanto seu móvel objeto" (Ferrara, 2008, p. 14).

O potencial de maior ou menor apreensão frente às idiossincrasias do conceito ganha corpo também nos argumentos de Irene Machado, que propõe "outra lógica" na expressão da ciência, uma lógica "não afeita a axiomas e postulados" (2008, p. 1). Ela examina uma hipótese contrária à que defende Wilson Gomes, em “O estranho caso de certos discursos epistemológicos que visitam a área da Comunicação", de $2003^{3}$. Ali, nas palavras de Machado, o autor "se ressente da falta de rigor na linguagem da ciência nas práticas discursivas da área" (Machado, 2008, p. 1). Gomes chama para o rigor, no melhor estilo da tradição científica ocidental. Machado, sem concessão ao puro ensaísmo, apresenta o ensaio como "possibilidade interpretativa" na construção de conhecimentos "fora dos limites restritivos do rigor da lógica tal como consagrada pela retórica clássica" (Machado, 2008, p. 2). Insiste ter "chegado à hora de qualifi- car a potencialidade retórica de linguagens perspectivadas pelas diferentes classes de signos dos sistemas de nossa cultura" (Machado, 2008, p. 2). Trabalhando a partir de uma atitude mental que cultiva um pensamento aberto a acolher as promessas e, também, os desafios do aquém, em e além do conceito, não enterra o "paradigma do rigor", como também não dispensa "o vigor de uma linguagem pouco favorável ao rigor da lógica. Muito aberta, contudo, ao diálogo interpretativo das interpretações e pontos de vista" (Machado, 2008, pp. 3-4) ${ }^{4}$.

\section{Considerações finais}

A frase de Shakespeare, de que "há mais mistérios entre o céu e a terra do que imagina nossa vã filosofia", talvez possa ser aplicada ao campo da comunicação, naquilo que ajuda a entender os rumos possíveis de um pensamento de matriz compreensiva. Um pensamento que não exclui, mas junta; que não descarta o que não cabe nos limites de uma disciplina a se fazer doutrina, mas que chama para a conversa e o diálogo; que sabe ver o ser e o não-ser em sua dialogia, a complementaridade dos opostos, a lógica não-lógica do paradoxo. Um pensamento em semelhante medida, humanamente compreensivo, de respeito e afeto para com quantos estão a caminho. Um pensamento que jamais imagina poder começar algo do zero, mas que entende sua existência e possibilidade de avanço na medida mesma em que se reconhece na intertextualidade dos sentidos e vozes plurais. Um pensamento que, não sendo dual, não se pretende único.

Um pensamento, mais que sistemático, ecossistemático. De interações de várias ordens, na desafiante tarefa de compreensão do mundo - e não de explicação, que o tempo não é de pontos finais. Um pensamento dado ao abraço, ao afeto, à cordialidade, bem além do que propõe a expressão "debate de idéias". Um pensamento que não abandone o vínculo com a vida, e que tem, por isso mesmo, em alta conta o valor da "saúde de espírito" de que fala Epicuro maAmecos

\section{NOTAS}

Trabalho apresentado ao GT Epistemologia da Comunicação, do XVIII Encontro da Compós, na PUCMG, Belo Horizonte, MG, em junho de 2009.

1 À conclusões semelhantes chega o autor em pesquisas com a literatura de língua francesa e inglesa. Voltando ao caso da língua espanhola, que ele toma aqui como exemplo, foram nove os livros estudados, com 72 teorias diferentes. "A conclusão é que ninguém concorda sobre quais são, de fato, as teorias da comunicação. Ou, mais precisamente, que temos em mente conjuntos e idéias muito diferentes quando empregamos a expressão 'teorias da comunicação'" (Martino, 2008, pp. 24-25).

2 Os textos dos encontros da Compós podem ser con- 
sultados no site da Associação (www.compos.org.br).

3 In: Maria Imacolatta Vassallo de Lopes (Org.), Epistemologia da Comunicação. São Paulo: Loyola, 2003, pp. 313-329.

4 Cf. o artigo de Irene Machado, "Controvérsias sobre a cientificidade da linguagem”, retrabalhado, em Líbero, revista do Programa de Pós-Graduação da Faculdade Cásper Líbero, ano XI, n. 22, dez 2008, pp. 63-74.

\section{REFERÊNCIAS}

CONTRERA, Malena. Em meio ao desencanto: a comunicação fundada no pensamento mecânico-funcional. Trabalho apresentado ao GT "Epistemologia da Comunicação" do XVI Encontro da Compós, em Curitiba, PR, junho de 2007.

DESCARTES, René. Discurso do método. $2^{\mathrm{a}}$. edição. São Paulo: Martins Fontes, 2003.

FERRARA, Lucrécia. Radical indeterminação: epistemologia e objeto científico da comunicação. Trabalho apresentado ao GT "Epistemologia da Comunicação" do XVII Encontro da Compós, em São Paulo, SP, junho de 2008.

KÜNSCH, Dimas A. e BARROS, Laan Mendes de (Orgs.). Comunicação: saber, arte ou ciência? Questões de teoria e epistemologia. São Paulo: Plêiade, 2008.

KÜNSCH, Dimas A. Teoria compreensiva da comunicação. In: KÜNSCH, Dimas A. e BARROS, Laan Mendes de (Orgs.). Comunicação: saber, arte ou ciência? Questões de teoria e epistemologia. São Paulo: Plêiade, 2008, pp. 173-195.

LIMA, Venício A. de. Mídia: teoria e política. $2^{a}$. edição. São Paulo: Perseu Abramo, 2004.

LOPES, Maria Immacolata Vassalo de. Comunicação, disciplinaridade e pensamento complexo. Trabalho apresentado ao GT “Epistemologia da Comunicação” do XVI Encontro da Compós, em Curitiba, PR, junho de 2007.

MACHADO, Irene. Controvérsias sobre a cientificidade da linguagem. Trabalho apresentado ao GT "Epistemologia da Comunicação" do XVII Encontro da Compós, em São Paulo, SP, junho de 2008.

MAFFESOLI, Michel. Elogio da razão sensível. $3^{\mathrm{a}}$. edição. Petrópolis: Vozes, 1998.

O conhecimento comum: introdução à sociologia com- preensiva. Porto Alegre: Sulina, 2007.

MARTINO, Luiz C. O campo da comunicação e suas teorias. In: KÜNSCH, Dimas A. e BARROS, Laan Mendes de (Orgs.). Comunicação: saber, arte ou ciência? Questões de teoria e epistemologia. São Paulo: Plêiade, 2008, pp. 13-33.

(Org.). Teorias da comunicação: muitas ou poucas? Cotia, SP: Ateliê Editorial, 2007.

De qual comunicação estamos falando? In: HOHLFELDT, Antonio, MARTINO, Luiz C. e FRANÇA, Vera Veiga (Orgs.). Teorias da comunicação: conceitos, escolas e tendências. 5a . edição. Petrópolis: Vozes, 2001.

. Abordagens e representação do campo comunicacional. Comunicação, mídia e consumo vol. 3, n. 8, nov. 2006, pp. 33-54.

MORIN, Edgar. Os sete saberes necessários à educação do futuro. $2^{\mathrm{a}}$. edição. São Paulo: Cortez; Brasília: Unesco, 2000.

PIMENTA, Francisco José Paoliello. Indeterminação; o 'admirável'; a crescente comunicabilidade. Trabalho apresentado ao GT "Epistemologia da Comunicação” do XVII Encontro da Compós, em São Paulo, SP, junho de 2008.

RESTREPO, Luis Carlos. O direito à ternura. $3^{\mathrm{a}}$. edição. Petrópolis: Vozes, 1998.

ROSSETTI, Regina. A linguagem como mediação da intuição. Trabalho apresentado ao GT “Epistemologia da Comunicação" do XVI Encontro da Compós, em Curitiba, PR, junho de 2007.

SODRÉ, Muniz. As estratégias sensíveis: afeto, mídia e política. Petrópolis: Vozes, 2006. 